\title{
Posttraumatic Stress after Treatment in an Intensive Care Unit
}

\author{
KK Wu, VW Cho, FL Chow, APY Tsang, DM Tse
}

\begin{abstract}
Objective: To study posttraumatic stress in patients after treatment in an intensive care unit (ICU).

Methods: This prospective cohort study included 136 adult patients with critical medical and surgical problems who were discharged from the ICU of the Caritas Medical Centre, Hong Kong. Their occurrence of posttraumatic stress disorder (PTSD), anxiety, and depression after ICU treatment were measured using the Impact of Event Scale-Revised and Hospital Anxiety and Depression Scale. Patient ICU experience was measured using the ICU Memory Tool. Multivariable analyses were conducted to examine the predictors of PTSD symptoms, anxiety, and depression.

Results: Symptoms of PTSD, anxiety, and depression were reported in $10 \%$ to $17 \%$ of patients. Symptom severity was associated with less factual memory, more vivid memory of feelings about and more delusional memory of the ICU experience, low emotional support, and high perceived life threat.

Conclusions: Symptoms of posttraumatic stress, anxiety, and depression may occur after ICU treatment. Early identification and appropriate intervention for PTSD are important for rehabilitation.
\end{abstract}

Key words: Anxiety; Critical care; Depression; Psychology, clinical; Stress disorders, post-traumatic

Dr Kitty $K W u, P h D, F H K P S, M$ Soc Sc (Clin Psy), Department of Clinical Psychology, Caritas Medical Centre, Hong Kong.

Dr Valda W Cho, PhD, M Soc Sc (Clin Psy), Department of Clinical Psychology, Caritas Medical Centre, Hong Kong.

Dr Fu-loi Chow, FHKCP, FHKAM (Medicine), Intensive Care Unit, Department of Medicine and Geriatrics, Caritas Medical Centre, Hong Kong.

Ms Angel PY Tsang, MSN, BSN, RM, RN, Intensive Care Unit, Department of Medicine and Geriatrics, Caritas Medical Centre, Hong Kong.

Dr Doris M Tse, FRCP, FHKAM (Medicine), Hospital Chief Executive, Caritas Medical Centre, Hong Kong.

Address for correspondence: $\mathrm{Dr}$ Kitty $\mathrm{K} W u$, Department of Clinical Psychology, Princess Margaret Hospital, 2-10 Princess Margaret Hospital Road, Lai Chi Kok, Kowloon, Hong Kong.

Tel: (852) 2990 8111, Fax: (852) 2990 3980; Email: wukyk@ha.org.hk

Submitted: 24 July 2017; Accepted: 10 January 2018

\section{Introduction}

Receiving treatment in an intensive care unit (ICU) can be both stressful and psychologically traumatic. The prevalence of posttraumatic stress disorder (PTSD) after ICU treatment has been reported to be $14 \%$ to $59 \% .^{1}$ In mechanically ventilated patients who had acute lung injury, $35 \%$ had PTSD symptoms at any point based on the mean cut-off score of the Impact of Event Scale-Revised (IES-R), of whom more than $60 \%$ were still affected after 2 years.,3 Identified risk factors for PTSD after ICU were longer ICU stay and longer duration of sepsis, whereas protective factors were longer duration of opioid and corticosteroid administration in the ICU., ${ }^{2,3}$ In a review comparing studies between periods from 1997 to 2007 and from 2008 to 2012, the prevalence of PTSD after ICU treatment was similar and ranged from $9 \%$ to $27 \%{ }^{4}$ Clinical risk factors for PTSD after ICU treatment were identified to be the use of benzodiazepines and the duration of sedation and mechanical ventilation, whereas psychological risk factors were experience of stress, fear, and frightening memories. ${ }^{4}$

Potentially traumatic elements related to ICU stay include pain, medical procedures, witnessing another patient dying, and circumstances of illness or injury before admission. ${ }^{5}$ These experiences have been reported by $78.7 \%$ of ICU patients and are unrelated to disease severity. Being therapeutically paralysed without being completely sedated could also be a risk factor for PTSD. ${ }^{6}$ Moreover, ICU experience may be stressful owing to association with awareness of painful procedures, sense of helplessness, loss of control, and imminent threat of death. ${ }^{7}$ Development of acute PTSD symptoms after intensive care is associated with multiple traumatic experiences during ICU stay and delusional memories without recall of factual events 2 weeks post-discharge. ${ }^{8}$ In an Australian study, PTSD symptoms were associated with higher levels of trait anxiety, younger age, mental health treatment before ICU admission, and more symptoms of anxiety after ICU discharge. ${ }^{9}$ These risk factors could be inter-related. For example, delirium was detected in $60 \%$ of the patients, and delirious patients were found to have fewer factual memories and more memories of delusion compared with non-delirious patients up to 6 months after ICU discharge. ${ }^{10}$

It is not certain if risk factors identified in western studies can be generalised across cultures. Studying the psychological morbidity in ICU patients could provide valuable information about risk/benefit analysis in the choice of ICU medication, monitoring of patients at 
risk of PTSD, improving post-ICU psychological care management by anticipating which patients are at risk of mental health problems, and early referral for psychological intervention and follow-up., ${ }^{2,3}$ This study aimed to determine the prevalence of PTSD, anxiety, and depression, and their risk factors among ICU-discharged patients.

\section{Methods}

This study was approved by the Kowloon West Cluster Research Ethics Committee of the Hospital Authority in Hong Kong (KW/EX/06-025). Informed consent was obtained from each patient. All adult patients with critical medical and surgical problems who were discharged from the ICU of the Caritas Medical Centre, Hong Kong, between April 2007 and March 2009 were contacted by a research assistant 1 week after discharge. Inclusion criteria were a Glasgow Coma Scale score of $\geq 13$, no head injury, and ability to complete the self-report questionnaire. Patients who had head injury or were unable to complete the selfreport measures in Chinese were excluded. Participants were asked to complete a battery of psychological selfreport measures, including IES-R, ${ }^{11,12}$ Hospital Anxiety and Depression Scale (HADS), ${ }^{13,14}$ and ICU Memory Tool (ICUMT) ${ }^{8}$ which was administered by the research assistant via face-to-face interview in hospital wards.

The IES-R ${ }^{11}$ is a widely used measure of PTSD symptoms in critical care. ${ }^{15}$ It captures DSM-IV PTSD symptomatic responses to a specific traumatic stressor (eg, intensive care for critical illness) in the previous week. Each item is rated on a 5-point Likert scale. There are 3 subscales (intrusion, avoidance, and hyperarousal), which have high internal consistency (Cronbach's alpha of 0.79 to 0.91 ) and test-retest reliability of 0.51 to $0.94 .{ }^{11}$ It is a good screening instrument for PTSD symptoms in various populations, including Asian populations. ${ }^{16}$ The Chinese version of the IES-R has good internal consistency and validity, compared with the clinician-administered PTSD scale, ${ }^{17}$ in detecting distress associated with PTSD among Chinese survivors of motor vehicle collisions; the Cronbach's alpha for the IES-R subscales was 0.86 to $0.92 .^{12,16,18}$ For the purpose of this study, a subscale score of 2 (moderate distress) was used as the reference point that necessitated clinical attention.

The HADS ${ }^{13}$ is commonly used to detect anxiety and depression symptoms in a general medical outpatient population. The Chinese version of HADS subscales have an internal consistency alpha of 0.74 to $0.81 .{ }^{14}$ Anxiety and depression are the most common co-morbidities of PTSD symptoms after a motor vehicle collision. ${ }^{19}$ The HADS is an alternative measure of psychological adjustment. For the purpose of this study, a HADS subscale score of 11 was used as the cut-off. The HADS was used to assess the relationship between PTSD features, anxiety, and depression.

The ICU-MT is used to measure the recall of events in the ICU. ${ }^{8}$ It consists of 11 items on memory of factual events (eg, the presence of an endotracheal tube), 7 items on memory of feelings (eg, pain, panic, or confusion), and 3 items on delusional memory (eg, paranoia or hallucination).

Disease severity was indicated by the number of days spent in the ICU, the highest score in acute physiology and chronic health evaluation II (APACHE II) in the first 24 hours,$^{20}$ and the highest score in therapeutic intervention scoring system (TISS). ${ }^{21}$ Higher APACHE II scores indicate a higher risk of death owing to lower consciousness level and inability to recall uncomfortable events. Higher TISS scores indicate more invasive procedural and nursing intervention and thus sicker patients. Both scores are comprehensive, comparable across patients, and were known instruments to indicate disease severity of ICU patients.

Patient age, sex, and ICU-related and psychosocial factors (eg, history of psychiatric consultation, history of traumatic experience, perceived emotional support, and level of perceived life threat related to the condition that led to ICU treatment) were collected using a questionnaire. Risk factors examined were age, sex, disease severity, and postICU psychological variables (eg, factual memory, memory of feelings, and delusional memory of ICU experience, low emotional support, and high perceived life threat).

Pearson's correlation test was used to determine the relationship among various factors. Multivariable analysis of variance and multiple regression analysis were conducted to examine the predictors of PTSD symptoms, anxiety, and depression. SPSS (Windows version 19; IBM Corp, Armonk [NY], United States) was used for data analysis.

\section{Results}

A total of 96 men and 40 women aged 18 to 78 years (mean, 50.9 years; standard deviation [SD], 16.5 years) were included. Ten of these patients reported having a history of psychiatric consultation. The 136 patients accounted for $21.9 \%$ of all ICU patients who fulfilled the inclusion criteria within the study period. The mean $\pm \mathrm{SD}$ duration from discharge from ICU to questionnaire completion was $16.35 \pm 9.89$ days. Among patients admitted to our hospital between 2007 and 2009, the mean length of stay in ICU was 4.32 days. Among the study participants, the mean length of stay in the ICU was 4.05 (range, 1-29) days; the mean highest APACHE II score was 16.45 (range, 2-43); and the mean highest TISS score was 23.31 (range, 8-43) [Table 1].

Non-participation was related to transfer to another hospital or readmission to the ICU (32.2\%), loss of contact (26.0\%), or refusal to participate $(19.9 \%)$. Participants and non-participants were comparable in terms of sex, history of psychiatric consultation, and duration of stay in the ICU, but participants were younger than non-participants $(50.89$ \pm 16.46 vs $61.28 \pm 18.10$ years; $F(1,617)=36.16 ; \mathrm{p}<$ $0.001)$.

The occurrence of memory of ICU experience was common; $110(78.5 \%)$ participants reported having memory of factual events; $82(58.6 \%)$ reported having memory of feelings, and $31(22.1 \%)$ reported having delusional memory.

For perceived life threat rated on a 5-point scale, of 
Table 1. Correlations among demographic variables, intensive care unit (ICU) variables, and psychosocial variables.

\begin{tabular}{|c|c|c|c|c|c|c|c|c|}
\hline \multirow[t]{3}{*}{ Variable } & \multirow{3}{*}{$\begin{array}{c}\text { Mean } \pm \text { SD } \\
\text { value }\end{array}$} & \multicolumn{7}{|c|}{ Pearson $r$} \\
\hline & & \multicolumn{4}{|c|}{$\begin{array}{l}\text { Impact of Event Scale- } \\
\text { Revised }\end{array}$} & \multicolumn{3}{|c|}{$\begin{array}{l}\text { Hospital Anxiety and } \\
\text { Depression Scale }\end{array}$} \\
\hline & & $\begin{array}{l}\text { Intru- } \\
\text { sion }\end{array}$ & $\begin{array}{l}\text { Avoid- } \\
\text { ance }\end{array}$ & $\begin{array}{l}\text { Hyper- } \\
\text { arousal }\end{array}$ & Total & Anxiety & $\begin{array}{l}\text { Depres- } \\
\text { sion }\end{array}$ & Total \\
\hline Female, No. $(\%)$ & $40(29.4 \%)$ & -0.02 & 0.01 & 0.00 & -0.01 & -0.02 & -0.07 & -0.05 \\
\hline Age, $y$ & $50.89 \pm 16.46$ & $-0.17^{*}$ & -0.11 & $-0.18^{*}$ & -0.17 & -0.09 & 0.02 & -0.03 \\
\hline Duration of ICU stay, $\mathrm{d}$ & $4.05 \pm 4.52$ & 0.05 & 0.05 & 0.03 & 0.05 & -0.01 & 0.09 & 0.05 \\
\hline $\begin{array}{l}\text { Acute physiology and chronic health } \\
\text { evaluation II in the first } 24 \text { hours }\end{array}$ & $16.45 \pm 7.93$ & -0.02 & 0.03 & -0.07 & -0.03 & 0.01 & 0.08 & 0.05 \\
\hline Therapeutic intervention scoring system & $23.31 \pm 7.19$ & -0.03 & 0.02 & -0.04 & -0.02 & 0.03 & 0.11 & 0.07 \\
\hline $\begin{array}{l}\text { Emotional support (4-point scale, } 1-4 \text {, } \\
\text { from no one to } \geq 4 \text { people with whom } \\
\text { the patient could talk and share worries) }\end{array}$ & $2.40 \pm 0.95$ & -0.16 & $-0.22^{\dagger}$ & $-0.20^{*}$ & $-0.21^{*}$ & $-0.27^{\dagger}$ & $-0.33^{\ddagger}$ & $-0.32^{\ddagger}$ \\
\hline $\begin{array}{l}\text { Perceived life threat (5-point scale, } 1-5, \\
\text { from not at all to extremely serious) }\end{array}$ & $2.54 \pm 1.22$ & $0.33^{\ddagger}$ & $0.28^{\prime}$ & 0.15 & $0.27^{\dagger}$ & $0.22^{\dagger}$ & $0.23^{\dagger}$ & $0.24^{\dagger}$ \\
\hline \multicolumn{9}{|l|}{ ICU Memory Tool } \\
\hline Factual memory & $4.16 \pm 2.87$ & -0.09 & -0.15 & -0.11 & -0.12 & -0.16 & -0.19 & -0.15 \\
\hline Memory of feelings & $1.63 \pm 1.61$ & $0.38^{\ddagger}$ & $0.35^{\ddagger}$ & $0.34^{\ddagger}$ & 0.38 & $0.45^{\ddagger}$ & $0.45^{\ddagger}$ & $0.47^{*}$ \\
\hline Delusional memory & $0.38 \pm 0.73$ & $0.35^{\ddagger}$ & $0.24^{\dagger}$ & $0.40^{\ddagger}$ & $0.36^{\ddagger}$ & $0.30^{\ddagger}$ & $0.26^{\dagger}$ & $0.30^{\ddagger}$ \\
\hline \multicolumn{9}{|l|}{ Impact of Event Scale-Revised } \\
\hline Intrusion & $0.78 \pm 0.79$ & & $0.80^{\ddagger}$ & $0.88^{\ddagger}$ & $0.96^{\ddagger}$ & $0.71^{\stackrel{t}{*}}$ & $0.60^{\ddagger}$ & $0.69^{\ddagger}$ \\
\hline Avoidance & $0.69 \pm 0.79$ & $0.80^{\ddagger}$ & & $0.78^{\ddagger}$ & $0.90^{\ddagger}$ & $0.67^{\stackrel{*}{*}}$ & $0.57^{\stackrel{*}{*}}$ & $0.66^{\ddagger}$ \\
\hline Hyperarousal & $0.67 \pm 0.62$ & $0.88^{\ddagger}$ & $0.78^{\ddagger}$ & & $0.95^{\ddagger}$ & $0.76^{\ddagger}$ & $0.65^{\ddagger}$ & $0.75^{\ddagger}$ \\
\hline Total & $2.13 \pm 2.07$ & $0.96^{\ddagger}$ & $0.90^{\ddagger}$ & $0.95^{\ddagger}$ & & $0.76^{\ddagger}$ & $0.65^{\ddagger}$ & $0.75^{\ddagger}$ \\
\hline \multicolumn{9}{|l|}{ Hospital Anxiety and Depression Scale } \\
\hline Anxiety & $4.84 \pm 4.81$ & $0.71^{\ddagger}$ & $0.68^{\ddagger}$ & $0.76^{\ddagger}$ & $0.76^{\ddagger}$ & & $0.78^{\ddagger}$ & $0.94^{\ddagger}$ \\
\hline Depression & $5.51 \pm 4.98$ & $0.60^{\ddagger}$ & $0.58^{\ddagger}$ & $0.65^{\ddagger}$ & $0.65^{\ddagger}$ & $0.78^{\ddagger}$ & & $0.95^{\ddagger}$ \\
\hline Total & $10.36 \pm 9.23$ & $0.69^{\ddagger}$ & $0.66^{\ddagger}$ & $0.75^{\ddagger}$ & $0.75^{\ddagger}$ & $0.94^{\ddagger}$ & $0.95^{\ddagger}$ & \\
\hline
\end{tabular}

the 136 patients, $30(22.1 \%)$ reported 'not at all', $46(33.8 \%)$ reported 'a little', 26 (19.1\%) reported 'moderately', 24 $(17.6 \%)$ reported 'quite serious', and $10(7.4 \%)$ reported 'extremely serious'. Regarding the number of people with whom the patients could talk and share their worries (emotional support) on a 4-point scale, of 134 patients who answered this item, 20 (14.9\%) indicated no one, 65 (48.5\%) indicated 1 to 2,25 (18.7\%) indicated 3 to 4 , and $24(17.9 \%)$ indicated $\geq 5$.

Of the 136 patients, 14 (10.3\%), 15 (11.0\%), and 6 (4.4\%) had a moderate level of distress in the intrusion, hyperarousal, and avoidance subscales of IES-R, respectively. Five $(3.7 \%)$ patients were considered to have PTSD because they had a moderate level of distress in all 3 subscales, whereas $14(10.3 \%)$ patients had a moderate level of distress in $1(5.9 \%)$ or $2(4.4 \%)$ subscales. In terms of HADS, 16 (11.8\%) and $23(16.9 \%)$ patients were considered to have anxiety and depression, respectively.

Results of MANOVA indicated that both sexes were comparable in terms of IES-R and HADS scores. IES-R and HADS scores were correlated $(r=0.75 ; \mathrm{p}<0.001)$. Age was associated with IES-R intrusion $(r=-0.17 ; \mathrm{p}<0.05)$ and hyperarousal $(r=-0.18 ; \mathrm{p}<0.05)$ subscale scores. Emotional support was associated with IES-R hyperarousal and avoidance subscale and total scores $(r=-0.20$ to -0.22 ; all $\mathrm{p}<0.05)$ and all HADS scores $(r=-0.27$ to -0.33 ; all $\mathrm{p}$ $<0.01)$. The perceived life threat was associated with IES-R intrusion and avoidance subscale and total scores $(r=0.27$ to 0.33 ; all $\mathrm{p}<0.01)$ and all HADS scores $(r=0.22$ to 0.24 ; all $\mathrm{p}<0.01)$. For ICU-MT, score in memory of feelings was associated with all scores in IES-R $(r=0.34$ to 0.38 ; all $\mathrm{p}<$ $0.001)$ and HADS ( $r=0.45$ to 0.47 ; all $\mathrm{p}<0.001)$, whereas 
score in delusional memory was associated with all scores in IES-R $(r=0.24$ to 0.40 ; all $\mathrm{p}<0.01)$ and HADS $(r=0.26$ to 0.30 ; all $\mathrm{p}<0.01)$.

Hierarchical multiple regression analysis was conducted to determine the contribution of various predictors to IES-R and HADS total scores. Predictors were entered in a hierarchical approach. Block 1 included age and sex; block 2 included ICU variables of disease severity and treatment invasiveness (length of stay in the ICU, APACHE, and TISS scores); and block 3 included postICU psychosocial variables (emotional support, perceived life threat, and ICU-MT scores). For IES-R total score, age and ICU variables accounted for only $3.1 \%$ of the variance. When post-ICU psychosocial variables were added, the model accounted for $35.3 \%$ of the variance $(F(10,122)=$ 6.65; $\mathrm{p}<0.001)$. Similarly for HADS total score, age and ICU variables accounted for $<1 \%$ of the variance. When post-ICU psychosocial variables were added, the model accounted for $28.2 \%$ of the variance $(F(10,122)=4.78$; p < $0.001)$. Post-ICU variables contributed significantly to the prediction of both scores (Table 2).

\section{Discussion}

The occurrence of PTSD symptoms in our ICU-discharged patients was comparable to that in Hong Kong Chinese patients who had been hospitalised for severe acute respiratory syndrome at 1 month post-discharge, with $12 \%$, $10 \%, 11 \%$, and $6 \%$ of patients having moderate distress in intrusion, avoidance, and hyperarousal subscales, and all 3 subscales, respectively. ${ }^{22,23}$ Occurrence of mental health symptoms secondary to ICU treatment highlights the potential risk of PTSD symptoms after ICU treatment and the importance of monitoring high-risk patients for early intervention.

Low emotional support and high perceived life threat are risk factors for developing PTSD features, anxiety, and depression after traumatic experience for Chinese patients. ${ }^{18,22,23}$ Our findings support that memory and delusions related to ICU treatment have a significant impact on the development of PTSD symptoms. The findings also indicate the importance of routine screening or monitoring of psychological adjustment for survivors of ICU treatment, especially for those who have less factual memory, more vivid memory of feelings about and more delusional memory of the ICU experience, low emotional support, and high perceived life threat. Routine screening of psychological distress related to PTSD, anxiety, and depression may facilitate early psychological or psychiatric assessment for clinical diagnosis and disability.

Early intervention by a clinical psychologist for ICU survivors and family members is associated with lower

Table 2. Results of multiple regression analysis to determine contribution of various predictors to Impact of Event ScaleRevised and Hospital Anxiety and Depression Scale scores.

\begin{tabular}{|c|c|c|c|c|c|c|}
\hline \multirow[t]{2}{*}{ Variables } & \multicolumn{3}{|c|}{$\begin{array}{l}\text { Impact of Event Scale- } \\
\text { Revised }\end{array}$} & \multicolumn{3}{|c|}{$\begin{array}{l}\text { Hospital Anxiety and } \\
\text { Depression Scale }\end{array}$} \\
\hline & $\boldsymbol{B}$ & SE $B$ & $\boldsymbol{\beta}$ & $\boldsymbol{B}$ & SE $B$ & $\boldsymbol{\beta}$ \\
\hline \multicolumn{7}{|l|}{ Block 1 (demographic variables) } \\
\hline Male sex & -0.08 & 0.33 & -0.02 & -0.04 & 0.11 & -0.03 \\
\hline Age & -0.02 & 0.01 & -0.15 & -0.00 & 0.00 & -0.04 \\
\hline \multicolumn{7}{|l|}{ Block 2 (intensive care unit [ICU] variables) } \\
\hline Duration of ICU stay & -0.03 & 0.04 & -0.07 & -0.02 & 0.01 & -0.12 \\
\hline $\begin{array}{l}\text { Acute physiology and chronic health evaluation II in the } \\
\text { first } 24 \text { hours }\end{array}$ & -0.01 & 0.02 & -0.03 & 0.00 & 0.01 & 0.03 \\
\hline Therapeutic intervention scoring system & -0.02 & 0.03 & -0.08 & -0.01 & 0.01 & -0.08 \\
\hline \multicolumn{7}{|l|}{ Block 3 (psychosocial variables) } \\
\hline $\begin{array}{l}\text { Emotional support (4-point scale, } 1-4 \text {, from no one to } \geq 4 \\
\text { people with whom the patient could talk and share worries) }\end{array}$ & -0.36 & 0.17 & $-0.17^{*}$ & -0.17 & 0.05 & $-0.26^{\dagger}$ \\
\hline $\begin{array}{l}\text { Perceived life threat (5-point scale, } 1-5 \text {, from not at all to } \\
\text { extremely serious) }\end{array}$ & 0.28 & 0.13 & $0.16^{*}$ & 0.32 & 0.04 & 0.06 \\
\hline \multicolumn{7}{|l|}{ ICU Memory Tool } \\
\hline Factual memory & -0.17 & 0.06 & $-0.23^{\dagger}$ & -0.03 & 0.02 & -0.14 \\
\hline Memory of feelings & 0.43 & 0.11 & $0.34^{\ddagger}$ & 0.16 & 0.04 & $0.41^{\ddagger}$ \\
\hline Delusional memory & 0.75 & 0.24 & $0.27^{\dagger}$ & 0.10 & 0.08 & 0.12 \\
\hline
\end{tabular}


levels of anxiety, depression, and PTSD, as well as lower requirement of psychiatric medication at 12 months postdischarge..$^{24}$ Our findings may serve as the baseline to explore the value of early identification and intervention of psychological problems related to ICU treatment for the Chinese population. Communication in the ICU is often hampered when the patient is intubated or sedated. Thus, support from family, provision of information, screening for delusional memories, and input from mental health professionals should be an integral part of ICU follow-up to enable early assessment and appropriate intervention. ${ }^{25,26}$ Provision of a diary outlining the patient's stay in ICU at 1 month post-discharge from ICU has been reported to reduce the incidence of new-onset PTSD. ${ }^{27}$ It is hypothesised that the diary may help to fill in the gaps of factual memory, place delusional memories into context, and support psychological recovery. ${ }^{27}$

An ICU experience could be traumatic. Occurrence of psychological morbidity in family members is likely, especially in those involved in end-of-life decisions and/or have faced the loss of loved ones. ${ }^{28,29}$ Future studies should evaluate the psychological adjustment of family caregivers and its relationship with the patient's condition.

Being therapeutically paralysed without being completely sedated when receiving intensive care could be a risk factor for PTSD. ${ }^{6}$ In our study, memory of feelings and delusional memory were risk factors. Although the negative bivariate correlation coefficients between ICU-MT factual memory and IES-R scores were not significant, ICU-MT factual memory was a significant predictor of IES-R total score in the regression analysis. This finding suggests that ICU-MT factual memory may be a protective factor for PTSD features, even though their correlation was small because of the variance secondary to other contributing factors. Further study on the relationship among various forms of ICU memories, effect of sedation level, and PTSD may help improve the practice of sedation in ICU.

Our study has some limitations. Generalisation of the findings is limited by a low participation rate of $21.9 \%$, because only patients with a Glasgow Coma Scale score of $\geq 13$ were included and some more-severe patients were excluded; participants were younger than non-participants. The occurrence of PTSD symptoms could not be taken as a prevalence estimate of the diagnostic condition. Diagnosis should be further substantiated by clinical interviews for PTSD to differentiate it from other diagnoses such as adjustment disorder. The mean period from ICU discharge to screening was only 2 weeks, and thus our findings indicate symptom occurrence in only the acute phase. Our study lacks measurement of baseline (or admission) mental health symptoms. This greatly limits the implication of the study findings. More long-term follow-up studies are required to assess chronic conditions. Symptoms need to last for at least 1 month to establish the diagnosis of PTSD. Memories of the ICU experience were examined using the ICU-MT, which relies on an individual's own recall without external validation. Furthermore, some risk factors were not included in the study, such as history of psychiatric disorder or substance abuse, pain, circumstances of the illness or injury that occurred before admission, and witnessing another patient dying. Comparisons of drugs used (eg, psychotropic, steroid, analgesic) in patients with different psychological outcomes could be contemplated for future investigation. Quality of life and functioning were not covered in our study.

\section{Conclusion}

Symptoms related to PTSD, anxiety, and depression may occur in ICU-discharged patients. Risk factors for early identification and appropriate intervention for PTSD were identified. This study highlights the importance of psychological care and identifies risk factors that need to be monitored for rehabilitation.

\section{References}

1. Tedstone JE, Tarrier N. Posttraumatic stress disorder following medical illness and treatment. Clin Psychol Rev 2003;23:409-88. Eross re

2. Bienvenu OJ, Colantuoni E, Mendez-Tellez PA, Shanholtz C, Dennison-Himmelfarb CR, Pronovost PJ, et al. Cooccurrence of and remission from general anxiety, depression, and posttraumatic stress disorder symptoms after acute lung injury: a 2-year longitudinal study. Crit Care Med 2015;43:642-53. Eross re

3. Bienvenu OJ, Gellar J, Althouse BM, Colantuoni E, Sricharoenchai T, Mendez-Tellez PA, et al. Post-traumatic stress disorder symptoms after acute lung injury: a 2-year prospective longitudinal study. Psychol Med 2013;43:2657-71. Eross ret

4. Wade D, Hardy R, Howell D, Mythen M. Identifying clinical and acute psychological risk factors for PTSD after critical care: a systematic review. Minerva Anesthesiol 2013;79:944-63.

5. Stoddard FJ, Todres ID. A new frontier: posttraumatic stress and its prevention, diagnosis, and treatment. Crit Care Med 2001;29:6878 . cross ret

6. Ballard N, Robley L, Barrett D, Fraser D, Mendoza I. Patients' recollections of therapeutic paralysis in the intensive care unit. Am J Crit Care 2006;15:86-94.

7. Jackson JC, Hart RP, Gordon SM, Hopkins RO, Girard TD, Ely EW. Post-traumatic stress disorder and post-traumatic stress symptoms following critical illness in medical intensive care unit patients: assessing the magnitude of the problem. Crit Care 2007;11:R27. cross ret

8. Jones C, Griffiths RD, Humphris G, Skirrow PM. Memory, delusions, and the development of acute posttraumatic stress disorder-related symptoms after intensive care. Crit Care Med 2001;29:573-80. cross re

9. Castillo MI, Cooke ML, Macfarlane B, Aitken LM. In ICU state anxiety is not associated with posttraumatic stress symptoms over six months after ICU discharge: a prospective study. Aust Crit Care 2016;29:158-64. eross re

10. Svenningsen H, Tønnesen EK, Videbech P, Frydenberg M, Christensen D, Egerod I. Intensive care delirium - effect on memories and healthrelated quality of life - a follow-up study. J Clin Nurs 2014;23:63444. cross re

11. Weiss DS, Marmar CR. The Impact of Event Scale-Revised. In: Wilson JP, Keane TM, eds. Assessing psychological trauma and PTSD: New York Guilford Press; 1997:399-411.

12. Wu KK, Chan KS. The development of the Chinese version of Impact of Event Scale-Revised (CIES-R). Soc Psychiatry Psychiatr Epidemiol 2003;38:94-8. cross re

13. Zigmond AS, Snaith RP. The hospital anxiety and depression scale. Acta Psychiatr Scand 1983;67:361-70. cross ret

14. Leung CM, Ho S, Kan CS, Hung CH, Chen CN. Evaluation of the Chinese version of the Hospital Anxiety and Depression Scale. A 
cross-cultural perspective. Int J Psychosom 1993;40:29-34.

15. Griffiths J, Fortune G, Barber V, Young JD. The prevalence of post traumatic stress disorder in survivors of ICU treatment: a systematic review. Intensive Care Med 2007;33:1506-18. Eross ret

16. Wu KK. Trauma assessments tools validated in Hong Kong. In: Wu KK, Tang CS, Leung EY, eds. Healing Trauma: A Professional Guide. Hong Kong: Hong Kong University Press; 2011:15-34.

17. Blake DD, Weathers FW, Nagy LM, Kaloupek DG, Gusman FD, Charney DS, et al. The development of a Clinician-Administered PTSD Scale. J Trauma Stress 1995;8:75-90. cross re

18. Wu KK, Cheung MW. Posttraumatic stress after a motor vehicle accident: a six-month follow-up study utilizing latent growth modeling. J Trauma Stress 2006;19:923-36. cross re

19. Blanchard EB, Hickling EJ. After the crash: assessment and treatment of motor vehicle accident survivors. 2nd ed. Washington DC: Am Psychol Assoc 2004.

20. Knaus WA, Draper EA, Wagner DP, Zimmerman JE. APACHE II: a severity of disease classification system. Crit Care Med 1985;13:81829. cross ret

21. Cullen DJ, Civetta JM, Briggs BA, Ferrara LC. Therapeutic intervention scoring system: a method for quantitative comparison of patient care. Crit Care Med 1974;2:57-60. cross ret

22. Wu KK, Chan SK, Ma TM. Posttraumatic stress, anxiety, and depression in survivors of severe acute respiratory syndrome (SARS). J Trauma Stress 2005; 18:39-42. Eross re
23. Wu KK, Chan SK, Ma TM. Posttraumatic stress after SARS. Emerg Infect Dis 2005;11:1297-300. Eross ret

24. Peris A, Bonizzoli M, Iozzelli D, Migliaccio ML, Zagli G, Bacchereti A, et al. Early intra-intensive care unit psychological intervention promotes recovery from post traumatic stress disorders, anxiety and depression symptoms in critically ill patients. Crit Care 2011;15:R41. Eross re

25. Cuthbertson BH, Hull A, Strachan M, Scott J. Post-traumatic stress disorder after critical illness requiring general intensive care. Intensive Care Med 2004;30:450-5. Eross re

26. Jones C, Skirrow P, Griffiths RD, Humphris GH, Ingleby S, Eddleston $\mathrm{J}$, et al. Rehabilitation after critical illness: a randomized, controlled trial. Crit Care Med 2003;31:2456-61. cross re

27. Jones C, Bäckman C, Capuzzo M, Egerod I, Flaatten H, Granja C, et al. Intensive care diaries reduce new onset post traumatic stress disorder following critical illness: a randomised, controlled trial. Crit Care 2010;14:R168. Eross ret

28. Azoulay E, Pochard F, Kentish-Barnes N, Chevret S, Aboab J, Adrie $\mathrm{C}$, et al. Risk of post-traumatic stress symptoms in family members of intensive care unit patients. Am J Respir Crit Care Med 2005;171:98794. Eross re

29. Jones C, Skirrow P, Griffiths RD, Humphris G, Ingleby S, Eddleston $\mathrm{J}$, et al. Post-traumatic stress disorder-related symptoms in relatives of patients following intensive care. Intensive Care Med 2004;30:45660 . eross re 